\title{
Dividendos e JuROS SOBRE 0 CAPITAL Próprio no Setor Petrolífero Brasileiro
}

\author{
O dilanei Morais dos Santos \\ Mestrando em CiênciasC ontábeis \\ Universidade Federal do Rio deJaneiro - FACC/ UFRJ \\ odilanei@facc.ufrj.br
}

Marcio de Araújo Resende

Mestrando em CiênciasContábeis UniversidadeFederal do Rio deJaneiro - FACC/ UFRJ maraujoresende@ig.oom.br

José A ugusto Veiga da Costa Marques

Doutor em Administração deEmpresaspela EAESP/ FGV Professor da FaculdadedeAdministração eCiênciasContábeisda Universidade Federal do Rio deJaneiro - FACC/ UFRJ joselaura@uol.com.br

\section{RESUMO}

Este estudo tem como objetivo investigar se as companhias abertas do setor petrolífero nacional remuneram adequadamente seus acionistas, quando se utilizam dos juros sobre 0 capital próprio. O u seja, o foco é verificar se estão imputando os JSCP adequadamente aos dividendos, isto é, se a imputação está ocorrendo unicamente aos dividendos obrigatónios. Foram selecionadas três companhias abertas do setor petrolífero nacional, da base de dados da CVM, que, no período de 2001 a2003, remuneraram seus acionistas por meio dos juros sobre o capital próprio. O s resultados da pesquisa mostraram que todas as companhias pesquisadas apresentaram algum problema, seja quanto àimputação dosjuros sobre o capital próprio aos dividendos obrigatórios, seja quanto à qualidade das informações. Isto demonstra que a questão da imputação dos juros sobre o capital próprio aos dividendos ainda gera confusão edúvidas, quanto ao tratamento adequado a ser dado pelas companhias.

PALAVRAS-CHAVE: juros sobre o capital próprio; dividendos; companhias petrolíferas.

\section{ABSTRACT}

Thisstudy hasasobjectiveto investigateiftheopen capital companies of thenational oil sector remuneratetheir shareholderssuitably, when they usetheinterestson owner's equity. Thefocusisto verify if such companiesareimputing itsdividendssuitably, in other words, if theimputation is being doneonly to thecompulsory dividends. Therewere selected threeopen capital companies, of thenational oil sector, of CVM'sdatabase, that, in theperiod from 2001 to 2003, remunerated their shareholdersthrough theinterestson owner'sequity. Theresultsshowed that all researched companiespresented someproblem, related to theimputation of theinterestson owner'sequity to thecompulsory dividends, or related to thequality of theinformation. It demonstratesthat the subject of theimputation of the interestson owner'sequity to thedividendsstill generates troubleand doubts, relating to thesuitabletreatment that the companieshaveto do in thisissue.

KEY WORDS: interestson owner'sequity; dividends; oil companies. 


\section{INTRODUÇÃO}

As companhias, ao apurarem lucro, têm como alternativas retê-lo em parte (reinvestindo na companhia) ou distribuí-lo aos seus acionistas, através de dividendos e dos Juros sobre o Capital Próprio.

Os dividendos consistem na destinação do lucro do exercício, dos lucros acumulados ou de reservas de lucros aos acionistas da companhia. Em casos especiais, as reservas de capital também podem ser utilizadas para o pagamento de dividendos às ações preferenciais.

Já os Juros sobre o Capital Próprio (JSCP), foram introduzidos pela Lei 9.249, de 26/ 12/ 1995 que, no seu art. 9o, faculta às empresas deduzir da base de cálculo do imposto sobre a renda, a título de remuneração do capital próprio, os juros pagos ou creditados a titular, sócio ou acionista, limitados à Taxa de Juros de Longo Prazo - TJLP.

Foi permitido às companhias imputar aos dividendos os JSCP pagos ou creditados aos acionistas. Entretanto, tal permissão se refere tão somente aos dividendos obrigatórios. D essaforma, este estudo tem como objetivo investigar se as companhias abertas do setor petrolífero nacional utilizamse dos JSCP para remunerar seus acionistas e, quando utilizam, se estão imputando adequadamente aos dividendos, ou seja, imputados unicamente aos dividendos obrigatórios.

O setor depetróleo no Brasil possuiparticipação significativanaeconomianacional, com crescenteincremento, principalmente após a regulamentação do setor por meio da lei $\mathrm{n}^{\mathbf{0}}$ 9.478/ 97, dentre outras, que compõe o seu marco regulatório, permitindo que outras companhias produzam ecomercializem no mercado nacional, bem como importem e exportem derivados de petróleo, fazendo, assim, com quea Petrobras deixassede ser aúnica executorado monopólio do petróleo daUnião.

D este modo, a relevância da presente pesquisa reside justamente na importância do setor de petróleo para aeconomia nacional. Ademais, em pesquisa recente, Costa Jr., Martins, Sousa Filho e Cardoso (2004) evidenciam a importância do tema, quando do estudo de 29 companhias abertas listadas na BO VESPA e que representaram as companhias que mais pagaram dividendos e/ ou JSCP, desde 1994 (11 delas fazem parte da carteira teórica do índice Ibovespa em vigor); somente 8 não cometeram erro relacionado à imputação dos JSCP ao dividendo obrigatório. Além disso, constatou-se ainda que 10 companhias prestaram informações conflitantes entre si nas publicações analisadas na pesquisa. Portanto, faz jus analisar como as companhias petrolíferas nacionais tratam o tema.

Ainda sobre o setor de petróleo, é importante destacar que o mesmo possui três grandes segmentos. Conforme Silva e Marques (2004), esses segmentos são:

- Exploração e Produção: atividades de construção, perfuração e produção necessária para extrair o óleo e o gás dos reservatórios subterrâneos, que são trazidos à superfície para serem separados.
- Refino: atividades de separação e processamento dos gases e hidrocarbonetos fluidos em vários produtos comercializáveis. O sprodutos derivados do refino e o líquido de gás natural (LGN) podem ser processados mais adianteem plantas petroquímicas. Alguns produtos petroquímicos podem, em troca, ser enviados às refinarias de óleo para mistura ou processamento com outros hidrocarbonetos líquidos, para elaborar vários produtos derivados, tal como a gasolina.

- Transporte, distribuição e estocagem: atividade de transporte dos campos de produção até as refinarias e plantas de processamento de gás. 0 óleo é transportado por dutos, caminhões, navios-tanque e barcaças. 0 gás natural é transportado por dutos. O s derivados e o gás liquefeito de petróleo (GLP ou "gás de cozinha") são transportados similarmente porvários meios até os pontos de distribuição de varejo, como os postos de gasolina.

Ainda segundo os autores, o segmento de Exploração e Produção é também chamado de atividades upstream e os outros 2 segmentos, de atividades de downstream. As companhias que possuem ambas as operações são verticalmente integradas na indústria do petróleo e, conseqüentemente, são chamadas integradas. O utras companhias envolvidas somente com o upstream, são chamadas independentes. Para a presente pesquisa, foram consideradas empresas que realizam atividades de upstream e downstream.

As limitações da pesquisa se dão pelo fato de quealgumas empresas pertencentes ao setor analisado são constituídas sob aforma de companhias fechadas e/ ou de responsabilidade limitada (Ltda.) e não disponibilizam seus demonstrativos financeiros publicamente. Tendo isto em vista, não foi possível abranger todas as empresas pertencentes ao setor de petróleo no Brasil. D essa forma, quando se tratar da análise do setor entende-se aquele formado por companhias abertas e que disponibilizaram dados publicamente.

\section{METO DO LO GIA UTILIZADA}

A presente pesquisa caracteriza-se como uma pesquisa descritiva, que, segundo Gil (1999) apud Beuren et al. (2003, p. 81), tem o objetivo principal de descrever características de determinada população ou fenômeno ou estabelecer relações entrevariáveis.

A pesquisa tem natureza qualitativa, umavez quea análise visou estudar a qualidade das informações evidenciadas pelas companhias.

A questão básica da pesquisa é: ascompanhiasabertas do setor petrolífero nacional, quando utilizam osJSCP para remunerar seusacionistas, estão imputando adequadamente osJSCP aos dividendosobrigatórios?

Para atender à questão básica da pesquisa, utilizaram-se as técnicas de pesquisas (a) bibliográfica, por ter sido elaborada com base em artigos, livros, revistas especializadas, sitesna 
internet, além de dissertações e textos, ou seja, "é desenvolvida a partir de material já elaborado" (G il, 1996, p.48) e (b) documental, por analisar os documentos produzidos pelas companhias pesquisadas e disponibilizados no siteda Comissão de V alores Mobiliários (CVM), tais como: relatório deadministração, demonstrações financeiras, notas explicativas, estatuto social eatas de reuniões.

Por fim, utilizou-se o estudo de caso, que, de acordo com Y in (1994), possibilita a investigação profunda de uma ou mais organizações, com o objetivo de testar a validade das hipóteses ou questões de pesquisa construídas a partir de um referencial teórico.

O setor pesquisado foi o petrolífero, por se tratar de uma indústria gigantesca que se encontra em plena expansão, movimenta grandes cifras diariamente, gera milhares de empregos, é grande contribuinte de tributos e tem participação relevante na economia do país.

Para seleção das companhias abertas do setor petrolífero, foi utilizada a base de dados da CVM (sistema D IVEXT). No levantamento realizado foram identificadas nove companhias, que disponibilizaram informações no período compreendido entre 2001 e2003. D essas, excluem-se quatro companhias, por fazerem parte de grupos econômicos cujas controladorasjá estavam contempladas na amostra. Com isso, aamostra inicial dapesquisa ficou restrita a cinco companhias e/ ou grupos econômicos. Contudo, quando das primeiras análises, constatou-se que duas companhias integrantes da amostra não utilizaram JSCP para remunerar seus acionistas, ficando assim, a amostra final composta por três companhias pertencentes ao setor analisado. As companhias foram denominadas de Cia A, Cia B e Cia C. A seguir, éfeita uma descrição genéricadas companhias selecionadas.

A CiaA iniciou suas atividades no ano de 1936, com a produção de derivados depetróleo, atividade principal da companhia até hoje. Em 2003, a companhia alterou o perfil de processamento, aumentando a participação de petróleos oriundos da costa oeste da África, buscando maximizar a produção do diesel, produto de maior valor agregado. Fazem parte do grupo econômico, uma refinaria, duas distribuidoras de derivados e uma petroquímica.

A Cia B foi fundada em 1946 e atua na produção, comercialização e distribuição de derivados de petróleo, bem como na prestação de serviços logísticos. Produz gás liquefeito de petróleo, diesel, gasolina, óleo combustível evários tipos de solventes e destilados especiais, que são comercializados para distribuidoras e indústrias. Fabrica ainda óleos, lubrificantes e graxas. Fazem parte do grupo econômico, uma refinaria, uma distribuidora de derivados e uma petroquímica.

A Cia C iniciou suas atividades em 1953, sendo líder em distribuição de derivados de petróleo no país e colocando-se entre as vintes maiores empresas petrolíferas mundiais. Proporcionou ao Brasil fazer parte desde 1997 do seleto grupo de 16 países que produzem mais de 1 milhão de barris deóleo por dia. Atua em todas as atividades do setor petrolífero, ou seja, operações de upstream e downstream. Fazem parte do grupo econômico, diversas subsidiárias, refinarias, distribuidoras, petroquímicas, geradoras de energias, dentre diversas outras empresas. Tem pormeta estratégica, tornar-se líderno mercado de petróleo, gás natural ederivados na América Latina, atuando como empresa integrada de energia, com expansão seletivada petroquímica e da atividadeinternacional.

A análise dos dados das companhias compreendeu três etapas, a saber: a primeira etapa consistiu no levantamento das informações societárias das companhias, constante de seus estatutos sociais, como espécies deações, quantidades deações, valor do capital social e direito conferido aos detentores de ações (existência de dividendos mínimos e/ ou fixos e obrigatórios). Tais informações constam do Q uadro 4.

No passo seguinte, sumarizaram-se as informações prestadas pelas companhias, relativas ao pagamento de dividendos e/ ou JSCP, tendo por base as A tas de A ssembléias, as D emonstrações Financeiras Padronizadas (D FP) e as Informações Anuais (IAN) constantes do sistema D IVEXT da CVM. Estas informações constam do Q uadro 5.

Por fim, evisando responderà questão básica da pesquisa, procedeu-se ao cálculo dos dividendos e/ ouJSCP, com base no arcabouço legal levantado enos critérios definidos pelos estatutos sociais das companhias, com o fito de identificar a parcela dos JSCP que poderiam ser imputados ao dividendo obrigatório e, conseqüentemente, seas companhias estão procedendo corretamente. Procedeu-se, também, àanálise qualitativa dos resultados obtidos em relação a evidenciação dasinformações. O s resultados dessa etapa constam do Q uadro 6.

\section{REVISÃO DA LITERATURA}

A remuneração dos recursos aplicados pelos acionistas num dado empreendimento corresponde ao lucro. Parte desse lucro é distribuída diretamente ao dono do capital e parteé reinvestida na empresa. Para este estudo, interessa a distribuição realizada diretamente aos acionistas, no caso os dividendose osJSCP.

\subsection{Dividendos}

Em se tratando de dividendos, conforme Costa Jr. (2004), representa uma importante parcela da remuneração conferida ao investidor, em retorno à poupança alocadaa uma dada sociedade. Corresponde a uma destinação do lucro do exercício, dos lucros acumulados e da reserva de lucros, sendo que, para o caso das ações preferenciais, poderão serutilizadas as reservas de capital em casos específicos.

D epreende-se da legislação societária as seguintes espécies de dividendos: dividendo obrigatório; dividendo fixo ou mínimo; dividendo prioritário; e dividendo cumulativo e não cumulativo. 
Por dividendo obrigatório, entende-se aqueleque os acionistas têm direito de receber, em cada exercício social, conforme estabelecido no estatuto social e poderá ser uma porcentagem do lucro ou do capital social ou um outro critério fixado com precisão e minúciae edesde que garantaigualdade de condições entre controladores enão controladores. No que serefere aos dividendos obrigatórios, as ações preferenciais possuem direitos adicionais em relação a esses dividendos, tais como 0 direito departiciparem igualdade de condições com as ordinárias; edereceber um dividendo, por ação preferencial, pelo menos $10 \%$ maior do que o atribuído a cadaação ordinária.

O dividendo fixo ou mínimo está no rol das vantagens conferidas às ações preferenciais (art. 17 da Lei 6.404/ 76) e se diferencia pelo fato de que, salvo disposição estatutária em contrário, as ações com direito a dividendos fixos não participam dos lucros remanescentes. Já as ações com direito a dividendos mínimos, participam dos lucros remanescentes (após lhe ser garantido o mínimo), em igualdade de condições com as ações ordinárias.

As ações com dividendo prioritário são aquelas queconferem a seus detentores prioridade na distribuição dos lucros, no reembolso do capital, com ou sem prêmio, ena acumulação dessas vantagens. Por exemplo: aLei 6.404/ 76 estabelece que as ações preferenciais podem ter prioridade no recebimento dos dividendos obrigatórios, de no mínimo 3\% do valor do patrimônio líquido da ação (art. 17, § 1o, inciso I, alínea a daLei no 6.404/ 76).

Porfim, as ações com dividendos cumulativos, conforme CostaJr. (2004), são aquelas que dão direito ao seu beneficiário de recebêllosno exercício em que houver lucros suficientes para sua distribuição, quando não for possível distribuí-lo no exercício social de sua competência $O$ não cumulativo, por dedução, não permite ao seu beneficiário enquadrar-senessasituação.

A decisão sobrea política de dividendos (espécies de dividendos a serem estabelecidosno estatuto, pagar ou reter, etc) é uma das principais decisões financeiras a serem to madas pelas empresas. Conforme Brealeye Myers (2000, p. 439), as decisões da empresa no tocante aos dividendosse misturam com outras decisões de financiamento e investimento. A questão que se deve responder é: qual o efeito de uma mudança no valor dos dividendos pagos, dados o orçamento de capital e as decisões de financiamento da empresa?

Segundo os autores, o dinheiro usado para financiar um aumento dos dividendos tem que vir de algum lugar. Se a empresa fixa os níveis de gastos com investimento e os financiamentos, há somente outra fonte de recurso - a emissão de ações. A política de dividendos é uma escolha entre, por um lado, reter os lucros e, por outro lado, pagar dividendos e emitir novas ações.

Segundo D amodaran (1997, p. 545), na metade dos anos 50, John Lintner realizou uma análise profunda do modo como as empresas norte-americanas fixavam o quanto do lucro seria pago como dividendos. Primeiro, as companhias fixavam a proporção do lucro que elas desejavam pagar sob a forma de dividendos. A seguir, as empresas decidiam sobrea fração dos lucros que elas desejavam pagar como dividendos no longo prazo. D epois, elas ajustavam os dividendos, vislumbrando o longo prazo e a estabilidade sustentável do lucro, aumentando o valor dos dividendos somente se percebessem que poderiam mantê-los estáveis.

D amodaran menciona, ainda, que há uma preocupação no tocante a alguns aspectos: a de precisar cortar dividendos; aos dividendosnão acompanharem o crescimento doslucros; $\mathrm{e}$ a manter um padrão de pouca oscilação. O s gerentes preocupam-se muito mais com as alterações nos valores dos dividendos do que com os níveis dos mesmos.

O ciclo de vida deuma empresaégeralmente traçado em termos de oportunidades de investimento e crescimento. As companhias, então, adotam políticas de dividendos de acordo com afase em que estejam em seu ciclo devida. A tabela seguinte resume a política de dividendos adotada nos quatro estágios da vidade uma companhia.

\begin{tabular}{|l|c|c|c|c|}
\cline { 2 - 5 } \multicolumn{1}{c|}{} & $\begin{array}{c}\text { Estágio 1 } \\
\text { Introdução }\end{array}$ & $\begin{array}{c}\text { Estágio 2 } \\
\text { Expansão Rápida }\end{array}$ & $\begin{array}{c}\text { Estágio 3 } \\
\text { Maturidade }\end{array}$ & $\begin{array}{c}\text { Estágio 4 } \\
\text { Declínio }\end{array}$ \\
\hline $\begin{array}{l}\text { Necessidade } \\
\text { de recursos }\end{array}$ & $\begin{array}{c}\text { Limitada pelo tamanho } \\
\text { da empresa e por outros } \\
\text { limites de infra-estrutura }\end{array}$ & $\begin{array}{c}\text { Alta, tendo em } \\
\text { vista o valor da } \\
\text { empresa }\end{array}$ & $\begin{array}{c}\text { Moderada, de } \\
\text { acordo com o valor } \\
\text { da firma }\end{array}$ & $\begin{array}{c}\text { Pequena, devido ao } \\
\text { declínio dos } \\
\text { projetos }\end{array}$ \\
\hline $\begin{array}{l}\text { Geração de } \\
\text { fluxos de caixa }\end{array}$ & $\begin{array}{c}\text { Negativos, em virtude } \\
\text { dos investimentos } \\
\text { realizados }\end{array}$ & $\begin{array}{c}\text { Aumenta, como } \\
\text { Baixo, em razão do } \\
\text { valor da empresa } \\
\text { uma percentagem } \\
\text { do valor da } \\
\text { companhia }\end{array}$ & $\begin{array}{c}\text { Alta, devido ao } \\
\text { valor da empresa }\end{array}$ \\
\hline dividendo & $\begin{array}{c}\text { Não há distribuição de } \\
\text { dividendos. Há emissão } \\
\text { de novas ações }\end{array}$ & $\begin{array}{c}\text { Não há distribuição } \\
\text { de dividendos ou se } \\
\text { distribuem baixos } \\
\text { valores de } \\
\text { dividendos }\end{array}$ & $\begin{array}{c}\text { Aumento do valor } \\
\text { dos dividendos }\end{array}$ & $\begin{array}{c}\text { Dividendos } \\
\text { especiais e } \\
\text { recompra de ações }\end{array}$ \\
\hline
\end{tabular}

Q uadro 1: A nálise da política de dividendos com base no ciclo de vida da empresa Fonte: Damodaran (1997, p. 547) 


\subsubsection{Cálculo dos Dividendos}

Um dos problemas que envolvem o cálculo dos dividendos diz respeito à existência de diversas classes ações, com direitos diversos. Em se tratando dos dividendos obrigatórios, o art. 202, § 4º da Lei 6.404/ 76 faculta aos órgãos da administração, quando a situação financeira da companhia não permitir, a não distribuição dos dividendos obrigatórios, registrando-os em reserva especial para serem pagos assim que a situação financeira da companhia permitir.

Contudo, em se tratando da existência de dividendos fixos ou mínimos, a companhia está obrigada legalmente a pagá-los (art. 203 da Lei 6.404/ 76), independentemente de sua situação financeira. $\mathrm{O}$ u seja, poderão existir casos em que a mesma terá que se endividar, para honrar seus compromissos frente aos acionistas.

Outro aspecto relacionado aos dividendos trata-se dos dispositivos relacionados à Reserva de Lucrosa Realizar pela Lei no 10.303/ 01, e que basicamente determina a constituição dessa reserva, quando o montante do dividendo obrigatório ultrapassar a parcela realizada do lucro líquido do exercício, sendo a referida reserva só utilizada para pagamento do dividendo obrigatório, quando realizada.

Feitas essas considerações, os acionistas têm direito de receber como dividendo a parcela dos lucros estabelecidano estatuto. Caso haja omissão do estatuto sobre o tema, deve ser observado o procedimento do art. 202, inciso I, da Lei $n^{0}$ 6.404/ 76, que prevêa metade do lucro líquido do exercício, diminuído ou acrescido da importância destinadaà constituição da reserva legal, e aimportância destinada à formação da reserva para contingências, além da reversão da mesma reserva formada em exencícios anteriores. Tal sistemática foi introduzida pela Lei 10.303/ 01 à Lei no 6.404/ 76.

\subsection{Juros Sobre o Capital Próprio}

OsJuros sobre o Capital Próprio (JSCP) foram regulamentados em 1995, por meio da Lei no 9.249, de 26 de dezembro do referido ano. 0 artigo 9o desta lei esuas alterações (em virtude da Lei no 9.430, de 30/ 12/ 96), tornam facultativa às empresas a dedução da base de cálculo do imposto sobrea renda, com o propósito de remuneraro capital próprio, dosjuros pagos ou creditados individualmente a titular, sócio ou acionista. Tais juros são calculados sobre as contas do patrimônio líquido e são limitados à variação, pro rata die, da Taxa de Juros de Longo Prazo - TJLP.

A legislação sobre este assunto e as normas da Receita Federal estipula que, para o valor dos JSCP serem dedutíveis na apuração do lucro real e da contribuição social, os mesmos devem ser debitados ao Resultado do Exercício como D espesa Financeira, tendo como contrapartida a conta ou sub-conta do exigível, que representa o direito de crédito do sócio ou acionista ou do titular da empresa individual. Para tanto, os juros pagos ou creditados ao titular, sócios ou acionistas, como forma de remunerar o capital próprio, devem obedecer aos seguintes limites, segundo as IN RF no $11 / 96 \mathrm{e}$ IN RF no 93/ 97:

1. 0 valor de tal remuneração tem que ser limitado à aplicação da TJLP sobre o montante do Patrimônio Líquido pro rata die, do exercício anterior, subtraindo, ainda, a Reserva de Reavaliação, caso ela não tenha sido adicionada às bases de cálculo do Imposto de Renda e da Contribuição Social;

2. 0 valor apurado, considerando o maior valor dos dois, deve se limitar a:

a) cinqüenta por cento do lucro do exercício, antes de sua contabilização; ou

b) cinqüenta por cento do saldo de lucros acumulados.

Para efeito de dedução na apuração do imposto derenda e contribuição social, além de respeitar os limites, as empresas devem registrar os JSCP como despesa financeira na demonstração do resultado, tornando-se assim uma despesa dedutível.

\subsubsection{Imputação dos Juros Sobre C apital Próprio aos Dividendos}

Uma das questões envolvendo a remuneração dos acionistas reside naimputação dos JSCP aos dividendos. Deacordo com a Lei no 9.249/ 95, os JSCP podem ser imputados ao valor do dividendo de que trata o art. 202 da Lei no 6.404/ 76, ou seja, ao dividendo obrigatório.

A CVM, por sua vez, editou norma (D eliberação no 207/ 96) na qual os JSCP devem ser imputados pelo valor líquido deIRRF ao dividendo obrigatório. Em realidade, devese ter atenção especial no caso da existênciade ações com direito a dividendos fixos ou mínimos, uma vez que a permissão da imputação recai apenas sobre dividendos obrigatórios.

\subsection{A spectos Financeiro, Fiscal e Contábil}

\subsubsection{A spectos Financeiros}

A dedução dos juros pagos ou creditados individualmente a titular, sócio ou acionista, para fins de remuneração do capital próprio, foi permitida para fatos geradores ocorridos a partir de 01/ 01/ 1996, com a entrada em vigor da Lein ${ }^{\circ}$ 9.249, de 26/ 12/ 1995.

Segundo a referida lei, a pessoajurídica poderá deduzir na determinação do lucro real, observando o regime de competência, os juros pagos ou creditados individualmentea titular, a título de remuneração do capital próprio, calculado sobre as contas do patrimônio líquido e limitados à variação pro rata dieda Taxa de Juros de Longo Prazo - TJLP.

D e acordo com 0 artigo 347, § 1으, do RIR/ 1999, o efetivo pagamento ou crédito dos juros fica condicionado a existência de lucros, computados antes da dedução dosjuros, ou de lucros acumulados e reservas de lucros, em montante 
igual ou superior ao valor de duas vezes os juros a serem pagos ou creditados.

Hávalores que não são consideradosno cálculo daremuneração sobre o patrimônio líquido, a menos que sejam adicionados para efeito de determinação do lucro real e da base de cálculo da contribuição social sobre o lucro líquido. São eles:

a) 0 valor da reserva de reavaliação de bens e direitos da

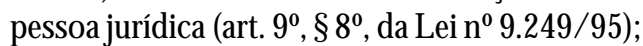

b) 0 valor da reserva especial relativaà correção monetária especial das contas do ativo, apurada na forma do D ecreto no 332/ 91, com base no IPC, prevista no RIR/ 1999, art. 460 (IN SRF no $11 / 96$, art. 29, § 2ㅇ, "b")

$\mathrm{O}$ valor dos juros pagos ou creditados poderá ser imputado ao valor dos dividendos obrigatórios a que os acionistas têm direito, conforme 0 art. 202 da Lei 6.404/ 76, mas haverá incidência de imposto de rendanafonte.

Segundo o artigo 1으, § único, da IN SRF no 41, de 22/ 04/ 1998, a utilização do valor creditado, líquido do imposto incidente na fonte, para integralização de aumentos de capital na empresa, não prejudica o direito de dedutibilidade da despesa, tanto para efeito do lucro real quanto da base de cálculo dacontribuição social sobre o lucro líquido.

D a mesmaforma como no caso dos dividendos, as companhias devem sempre observara questão dacapacidadefinanceira para pagamento dosJSCP, pois poderão ocorrer situações em que exista lucro (lucro econômico), mas a companhia não dispõe de recursos para o pagamento efetivo dosJSCP.

Assim sendo, a decisão da distribuição de JSCP sempre vai fazer parte das decisões financeiras das companhias, mesmo que osJSCP tragam benefícios econômicos e fiscais.

\subsubsection{Aspectos Fiscais}

Segundo 0 art. 347 do RIR/ 1999, os juros sobre 0 capital social sujeitam-se à incidência do imposto de renda na fonte (alíquota de 15\%), na data do pagamento ou crédito. Os referidos juros serão tratados no beneficiário, conforme mostra 0 quadro a seguir:

\begin{tabular}{|c|c|}
\hline $\begin{array}{l}\text { a) pessoas jurídicas tributadas com base } \\
\text { no lucro real }\end{array}$ & $\begin{array}{l}\text { - valor dos juros considerado como receeita financeira } \\
\text { imposto retido pela fonte pagadora é considerado como } \\
\text { antecipação do devido no encerramento do período de apuração ou } \\
\text { poderá ser compensado com aquele que houver retido, por ocasião } \\
\text { do pagamento ou crédito de juros a título de remuneração do } \\
\text { capital próprio, ao seu titular, sócios ou acionistas }\end{array}$ \\
\hline $\begin{array}{l}\text { b) pessoas juridicas tributadas pelo } \\
\text { lucro presumido ou lucro arbitrado }\end{array}$ & $\begin{array}{l}\text { - a partir de } 1^{\circ} / 01 / 1997 \text { - juros recebidos integram a base de } \\
\text { cálculo do imposto de renda e o valor do imposto retido na fonte } \\
\text { será considerado antecipação do devido no período de apuraçảo } \\
\text { (art. } 51 \text { da Lei } 9.430 / 96 \text { ) }\end{array}$ \\
\hline $\begin{array}{l}\text { c) pessoas jurídicas não tributadas com } \\
\text { base no lucro real, lucro presumido ou } \\
\text { arbitrado, inclusive isentas, e pessoas } \\
\text { físicas }\end{array}$ & $\begin{array}{l}\text { juros considerados como rendimento de tributação delinitiva. Isto } \\
\text { significa que os respectivos valores não serão incluídos nas } \\
\text { declarações de rendimentos, nem o imposto de renda que for retido } \\
\text { na fonte poderá ser objeto de qualquer compensação }\end{array}$ \\
\hline
\end{tabular}

Q uadro 2: Tratamento dos Juros sobre C apital Próprio no Beneficiário

Fonte: N eves e Viceconti (2001, p. 374-376)
O art. 1을 da IN SRF no 12/ 1999 estipula que aos juros e outros encargos pagos ou creditados pela pessoa jurídica a seus sócios ou acionistas, calculados sobre os juros remuneratórios do capital próprio e sobre os lucros e dividendos por ela distribuídos, são aplicadas as normas referentes aos rendimentos de aplicações financeiras de renda fixa, inclusive quanto ao informe a ser fornecido pela pessoa jurídica.

Já 0 art. 3ํㅡㄹ desta mesma norma, determina que 0 imposto de renda não incide sobre 0 valor dosjuros pagos ou creditados, caso a pessoa jurídica sejaimune. 0 art. 90 daLei $n^{0}$ 9.249/ 95 proporcionou, no ano-calendário de 1996, a opção de a pessoa jurídica incorporar o valor dos juros ao capital social ou manter em conta de reserva destinadaa aumento de capital, garantida a sua dedutibilidade para fins do lucro real, desde que a pessoa jurídica distribuidora assumisse 0 imposto de renda retido na fonte.

Tal dispositivo foi revogado pelo art. 88, inciso XXVI, da Lei no 9.430/ 96, mas, de acordo com o parágrafo único do art. 1ํda IN SRF no 41/ 1998, a utilização do valor creditado, líquido do imposto incidentena fonte, para integralização de aumento de capital na empresa, não prejudica o direito a dedutibilidade da despesa, tanto para efeito do lucro real, quanto da base de cálculo da contribuição social.

Os juros sobre o capital próprio passaram a ser dedutíveis para efeito de apuração da base de cálculo da contribuição social sobre o lucro líquido, a partir de 1ㅇ 01/ 1997.

D eacordo com o PN CST no 20/ 1987, "o lucro líquido, que servirá de base para determinação do lucro real de cada período-base, semestral ou anual, deve ser apurado segundo os procedimentos usuais de contabilidade, inclusive com o encerramento das contas de resultado" . A inda conforme este parecer, "a apuração do lucro líquido exige a transferência dos saldos das contas de receitas, custos e despesas para umaconta única de resultado, passando a integrar o patrimônio líquido, com o encerramento do período-base, mediante lançamentos para contas de reservas e de lucros ou prejuízos acumulados".

D esta forma, o resultado do próprio período de apuração somente serácomputado no patrimônio líquido, que servirá de base de cálculo dos juros sobre o capital próprio, apósasuatransferência para as contas de reservas ou de lucros ou prejuízos acumulados.

Há, ainda, outras hipóteses em quealegislação fiscal admite a dedução de juros sobrecapital próprio, na apuração do lucro real:

a) aamortização dos juros pagos ou creditados aos acionistas durante 0 período que anteceder 0 
início das operações sociais, ou de implantação do empreendimento inicial;

b) os juros pagos pelas cooperativas a seus associados, de até $12 \%$ ao ano sobre o capital integralizado.

Quanto aos efeitos nas empresas e aos respectivos beneficiários, Silva (1997, p. 79-80) apud Soares Jr. (2001, p. 61) aponta que os juros sobre o capital próprio são dedutiveis para fins de imposto de renda da pessoa jurídica e, a partir de 1\%/ 01/ 1997, também para fins da contribuição sobre o lucro. Q uando tais juros são pagos, há incidência de IRRF à alíquota de 15\%. Embora os dividendos sejam rendimentos isentos desde 1ㅇ / 01/ 96, não são dedutíveis para fins fiscais.

Ainda de acordo com o autor, o valor registrado como despesana investida terácomo contrapartidao correspondente registro de receita tributadana pessoajuńdicaqueo recebe. Logo, avantagem fiscal só seráalcançada quando o beneficiánio final do juro forpessoafísica, ou pessoajurídica com prejuízo real a compensar, ou ainda um residente ou domiciliado no exterior.

A distribuição dos juros que remuneram o capital próprio sujeita a empresa ao imposto de renda retido na fonte de $15 \%$ do seu valor. Todavia, proporciona redução do IRPJ e da CSLL, de aproximadamente 43\% para instituições financeiras, e em torno de $33 \%$ para empresas de outros ramos. Jáa utilização dosjuros sobre o capital próprio, rende uma economia tributária, respectivamente, de 28\% e 18\% (G ruginski, 1997, p. 23 apud Soares Jr., 2001, p. 62).

Analisando os períodos deapuração posterioresa 1997, Higuchi e Higuchi (1997, p. 47-8) apud SoaresJr. (2001, p. 6263) destacaaimportância da revo gação do $§ 10$ do art. 90 da Lei no - 9.249/ 95. Estaalteração propiciou a dedução dosjuros sobre o capital próprio, tanto na determinação do lucro real quanto da base de cálculo da CSLL. Tendo isto em vista, aspessoas jurídicas não sujeitas ao adicional de $10 \%$ passaram a ter vantagem fiscal de $8 \%$ naCSLL, ao passo que empresas que se sujeitavam ao adicional teriam 18\% da referidavantagem, sendo 8\% daCSLL e 10\% do adicional do IRPJ. Asinstituiçõesfinanceiras poderiam auferir uma vantagem ainda maior, por estarem sujeitas auma alíquotamais elevadadeCSLL.

O pagamento de JSCP é uma alternativa para reduzir a carga tributária. Porém, para se visualizar corretamente apossível vantagem, deve-se procedera uma análise do beneficiário dos rendimentos. Brito (1999, p. 64-5) apud SoaresJr. (2001, p. 63) relaciona 0 efeito fiscal com a natureza do beneficiário, daforma demonstrada no quadro abaixo.
Segundo Neves eViceconti (2001, p. 377-378), haverá economia deCSLL, quando o beneficiário for pessoa física, pois os juros sobre o capital próprio proporcionarão menor carga tributária, já que existirá compensação do ônus de 15\% de IRRF com o abatimento do IRPJ, que possui a mesma alíquota. Estes autores afirmam também, que, no caso da fonte pagadora serpessoajurídica sujeita ao adicional de 10\%, ocorrerá uma economia tributária ainda maior.

D o ponto de vista do ônus tributário, é indiferente remunerar o capital próprio, quando:

a) a pessoajurídica investida (fonte pagadora) e a pessoajurídica investidora (beneficiária) não estiverem sujeitas ao adicional do IRPJ;

b) tanto a pessoa jurídica pagadora, quanto à pessoa jurídica beneficiária estiverem sujeitas ao adicional.

Já quando a pessoajurídica beneficiária não estiver sujeita ao adicional ea pessoajurídica pagadora estiver, a economia tributária será de 10\%. Caso ocorra o contrário, não convém efetuar a distribuição.

\subsubsection{A spectos C ontábeis}

Conforme legislação regulamentar dos JSCP, o tratamento contábil a ser dispensado aos mesmos, para que seja considerada a sua dedutibilidade, é tratá-los como despesa financeira na demonstração do resultado.

Segundo Iudícibus, Martins e G elbke (2000, p. 274) a contabilização desses juros como despesa financeira, como determinado pela lei, implica graves prejuízos à comparabilidade das demonstrações contábeis, já que, como essesjuros são facultativos, algumas empresas os contabilizam e outras não. Além disso, a comparabilidade fica ainda mais prejudicada com a limitação do seu valorà metade do saldo de lucros acumulados, fazendo com que algumas empresas não possam considerá-la na sua integridade.

Tratam-se osJSCP, naverdade, de distribuição de resultado. Como comenta CostaJr. (2004, p. 2), "o fato dos JSCP ser função do lucro, serimputado ao dividendo obrigatório e não refletir de fato o custo de capital próprio, os JSCP, em essência, nada mais são do que uma destinação de parte do resultado apurado em um exercício social" . Como conseqüência, devem ser evidenciados na demonstração de mutação do patrimônio líquido.

Com esseentendimento, aCVM, por meio daInstrução no 207/ 96, determinou que os JSCP sejam contabilizadoscomo destinações de lucros, diretamentenacontalucros acumulados, sem transitar pelo Resultado do Exercício. D estaforma, as companhiasabertas que tiverem contabilizado tais juros como despesa financeira, objetivando a dedutibilidadefiscal, são obrigadas a efetuar areversão deseu valor, naúltimalinha da demonstração de resultado.

\section{Fonte: Soares Jr. (2001, p. 63)}


É importante frisar que esse procedimento é obrigatório apenas às companhias abertas. Com isso, temos empresas que procedem dessa maneira e outras não, prejudicando a comparabilidade entre elas. Ademais, mesmo considerando aquelas que adotam essa sistemática, a comparabilidade ainda fica prejudicada, pois várias delas não individualizam essa transação em linhas da D RE, nem em notas explicativas.

\section{ANÁLISE E RESULTADO S DA PESQ UISA}

Do levantamento das informações societárias das companhias analisadas, constantes do Tabela 4, destacam-se os seguintes dados relevantes:

$\mathrm{NaCiaA}$, não existeindicação de dividendos mínimose/ ou fixos, apenas de dividendos obrigatórios, queé de $30 \%$ do lucro líquido ajustado. As ações preferenciais possuem direito a dividendos $10 \%$ maiores que os dividendos conferidos às ações ordinárias, que correspondeao dividendo obrigatório. Houve distribuição de resultadosreferentes apenas ao exercício de 2001.

$\mathrm{NaCiaB}$, tanto as ações ordinámias quanto as preferenciais possuem direito a dividendos mínimos, comespondentes a 25\% do lucro líquido ajustado ou 10\% do capital social integralizado, dos dois o maior. O s dividendos mínimos das ações preferenciais correspondem a valores $10 \%$ maiores que os dividendos mínimos conferidos às ações ordinárias (em 2001, todas as ações possuíam os mesmos direitos). Houve distribuição de resultados referentes aos três exercícios pesquisados.

$\mathrm{NaCiaC}$, as ações preferenciais possuem direito a um dividendo mínimo prioritário, correspondente $5 \%$ do capital social relativo a essa classe de ação, ou a 3\% do valor patrimonial da ação, dos dois o maior. As ações ordinárias possuem direito apenas aos dividendos obrigatórios, que são de $25 \%$ do lucro líquido ajustado. Houve distribuição de resultados referentes aos três exercícios pesquisados.

Em relação àsinformações prestadas pelas companhias, relativas à distribuição dos resultados e constantes do Ta- bela 5, destacam-se os seguintes dados:

A Cia A, no exercício de 2001, distribuiu resultados na modalidade de JSCP num montante de $\mathrm{R} \$ 24,9$ milhões, líquidos de imposto de renda, imputados totalmente aos dividendos totais declarados.

A Cia B distribuiu, no exercício de 2001, o montante de $\mathrm{R} \$ 4,4$ milhões na modalidade de dividendos e $\mathrm{R} \$ 10,6 \mathrm{mi}$ lhões (líquidos de IR) como JSCP, que foram imputados aos dividendos obrigatórios. Já nos exercícios de 2002 e 2003, a companhia distribuiu somente JSCP, num montante de R \$ 12,8 milhões (líquidos IR) em cada exercício eque foram imputados aos dividendos totais declarados.

A Cia C distribuiu a título de JSCP (valores brutos) os montantes de R $\$ 2,1$ bilhões; $R$ \$2,2 bilhões; e R 4 4,6 bilhões; e a título de dividendos, $\mathrm{R} \$ 1,4$ bilhão; R 0,6 bilhão; e R 1,1 bilhão; todos relativos aos exercícios de 2001, 2002 e 2003, respectivamente. O sJSCP (valores brutos) foram imputados aos dividendos obrigatórios.

Por fim, na última etapa da pesquisa, aplicaram-se os critérios definidos nos estatutos das companhias, para remuneração dos acionistas, visando identificar se os JSCP foram imputados tão somente aos dividendos obrigatórios. Tais informações constam do Tabela 6 .

Ademais, procedeu-se à análise qualitativa, quanto a evidenciação das informações divulgadas. Seguem, abaixo, os resultados obtidos:

$\mathrm{Na}$ Cia A, o valor dos JSCP por ação foi maior que o valor do dividendo obrigatório por ação. A companhia imputou todo o JSCP declarado, mesmo que líquido de IR, aos dividendos, não distinguindo a parcela relativa aos dividendos obrigatórios, que ficaram "por dentro" dos JSCP por ação distribuídos, da parcela dos JSCP complementares. D essa forma, a companhia incorreu na inobservância de suas regras societárias, quando o valor a ser imputado aos dividendos obrigatórios seria de $\mathrm{R} \$ 5,0$ milhões e o restante, $\mathrm{R} \$ 15,9$ milhões, declarados como JSCP complementares.

Tabela 4: Levantamento das Informações Societárias

\begin{tabular}{|c|c|c|c|c|c|c|c|c|c|c|c|c|c|c|c|c|}
\hline \multirow{2}{*}{ Companhias } & \multirow{2}{*}{ Período } & \multicolumn{2}{|c|}{ Quantidade de Açöes } & \multicolumn{2}{|c|}{ Informaçőes Estatutárias } & \multicolumn{3}{|c|}{\begin{tabular}{|c|}
$\begin{array}{c}\text { Espédies de Dividendos } \\
\text { (MinFFixos) }\end{array}$ \\
\end{tabular}} & \multirow{2}{*}{$\begin{array}{l}\text { 㗱 do } \\
\text { Capital } \\
\text { Social } \\
\text { Curp! }\end{array}$} & \multirow{2}{*}{$\left|\begin{array}{c}\text { \% do VPLA } \\
\text { (Mr piaçäo) }\end{array}\right|$} & \multirow{2}{*}{$\begin{array}{c}\text { Lucro } \\
\text { Líquido } \\
\text { Ajustado } \\
\text { njacão } \\
\end{array}$} & \multirow{2}{*}{$\begin{array}{l}\text { Limite do } \\
\text { JSCP } \\
\text { piação }\end{array}$} & \multicolumn{2}{|c|}{$\begin{array}{c}\text { Dividendo MínimoFixo } \\
\text { p/açäo }\end{array}$} & \multirow{2}{*}{$\begin{array}{l}\text { Dividendo } \\
\text { Obrigatório }\end{array}$} & \multirow{2}{*}{$\begin{array}{c}\text { JSCP Pago } \\
\text { plaçäo }\end{array}$} \\
\hline & & Ord. & Pref. A & Ord. & Pref. A & Ord. & Pref. A & Obrig. & & & & & Ord. & Pref. A & & \\
\hline \multirow{3}{*}{ CIA A } & 2003 & 4.991 .202 & 9.808 .798 & Obrigatório & $10 \%>$ Ord. & Nẫo & Nẫo & $30 \%$ & Nap & Nap & 0,0072800 & Nap & Nap & Nap & 0,0000000 & 0,0000000 \\
\hline & 2002 & 4.991 .202 & 9.808 .798 & Obrigatório & $10 \%>$ Ord. & Nẫo & Nẵo & $30 \%$ & Nap & Nap & $(0,0200600)$ & Nap & Nap & Nap & 0,0000000 & 0,0000000 \\
\hline & 2001 & 4.991 .202 .320 & 9.808 .797 .680 & Obrigatório & $10 \%>$ Ord & Nẵo & Nẳ0 & $30 \%$ & Nap & Nap & 0,0010613 & 0,0023091 & Nap & Nap & 0,0003184 & 0,0018546 \\
\hline \multirow{3}{*}{ CIA B } & 2003 & 87.601 .197 & 16.723 .654 & $25 \%$ LL ou $10 \% \mathrm{CS}$ & $10 \%>$ Ord & Mínimo & Mínimo & $25 \%$ & 0,0196326 & Nap & 0,1487086 & 0,2031227 & 0,0371771 & 0,0408949 & 0,0371771 & 0,1415132 \\
\hline & 2002 & 87.601 .197 & 16.723 .654 & $25 \%$ LL ou $10 \% \mathrm{CS}$ & $10 \%=$ Ord. & Mínimo & Mínimo & $25 \%$ & 0,0196326 & Nap & 0,1909804 & 0,1697786 & 0,0477451 & 0,0525196 & 0,0477451 & 0,1415132 \\
\hline & 2001 & 87.601 .197 & 16.723 .654 & $25 \% \mathrm{LL}$ ou $10 \% \mathrm{CS}$ & $25 \% \mathrm{LL}$ ou $10 \% \mathrm{CS}$ & Mínimo & Mínimo & $25 \%$ & 0,0196326 & Nap & 0,5755388 & 0,1237285 & 0,1438847 & 0,1438847 & 0,1438847 & 0,1173670 \\
\hline \multirow{3}{*}{ CIAC } & 2003 & 634.168 .418 & 462.369 .507 & Obrigatório & $5 \% \mathrm{CS}$ ou $3 \%$ VPLA & Nã̃o & min priori & $25 \%$ & 0,9211374 & 1,4114853 & 17,3674394 & 4,155950 & Nap & 1,4114853 & 4,3418599 & 4,1500000 \\
\hline & 2002 & 634.168 .418 & 461.802 .497 & Obrigatório & $5 \% \mathrm{CS}$ ou $3 \%$ VPLA & Nẵo & min priori & $25 \%$ & 0,7587276 & 1,0065248 & 8,5079411 & 2,677686 & Nap & 1,0065248 & 2,1269853 & 2,0000000 \\
\hline & 2001 & 634.168 .418 & 451.935 .669 & Obrigatório & $5 \% \mathrm{CS}$ ou $3 \%$ VPLA & Nẫo & min priori & $25 \%$ & 0,6156204 & 0,8206554 & 11,6592002 & 2,010805 & Nap & 0,8206554 & 2,9148001 & 1,9700000 \\
\hline
\end{tabular}

Fonte: os autores 
A evidenciação dasinformaçõesnão foi suficiente para o correto entendimento da distribuição dos resultados. A Cia não evidenciou os cálculos dos dividendos devidos, informando apenas o valor dos JSCP declarados.

A Cia B, no exercício de 2001, imputou corretamente os JSCP aos dividendos obrigatórios, atéporqueosJSCP por ação estavam "por dentro" dos dividendos obrigatórios poração. A evidenciação dasinformações mostrou-se adequadaemantinha coerênciaao divulgado em DFP, A tas, IAN eNotas Explicativas.

Contudo, nos exercícios de 2002 e 2003, os JSCP foram incorretamente imputados aos dividendos (os dividendos obrigatório e mínimo por ação estavam "por dentro" dos JSCP por ação). Em 2002, o valor de JSCP a ser imputado aos dividendos obrigatórios seria de $\mathrm{R} \$ 5,1$ milhões e o restante, R \$ 7,7 milhões, como JSCP complementares. Já em 2003, o valor de JSCP a ser imputado aos dividendos obrigatórios seria de $\mathrm{R} \$ 4,0$ milhões, enquanto outros $\mathrm{R} \$ 8,8$ milhões como JSCP complementares.

Em 2002 e 2003, a companhia demonstrou em notas explicativas o cálculo dos dividendos obrigatórios e dividen- dos pagos antecipadamente, mas no IAN, A tas e D FP informaapenas a distribuição deJSCP, prejudicando a evidenciação dasinformações.

$\mathrm{NaCiaC}$, nos exercícios de 2001, 2002 e 2003, os JSCP por ação estavam "por dentro" dos dividendos obrigatórios por ação, o mesmo acontecendo com os dividendos mínimos por ação preferencial. D essa forma, o valor distribuído como JSCP poderia ser, e foi, imputado integralmente aos dividendos obrigatórios. A falha da Cia reside no fato de não evidenciar o valor líquido de IR dos JSCP, que estão sendo imputados aos dividendos obrigatórios.

Quanto à qualidade das informações, éimportante ressaltar que em suas atas, no IAN e no D FP consta a informação de que a companhia distribuiu apenas dividendos, enquanto suas notas explicativas evidenciam que distribuiu tanto dividendos como JSCP. Um ponto de destaque, em relação a evidenciação das informações, reside no fato da companhia divulgar dados relativos à economia fiscal gerada pelos JSCP, quais sejam: R \$ 0,7 bilhão em 2001; R \$ 0,7 bilhão em 2002; e R\$1,5 bilhão em 2003.

Tabela 5: D istribuição dos Resultados de A cordo com as Informações Prestadas pelas Companhias

\begin{tabular}{|c|c|c|c|c|c|c|c|c|c|c|c|c|c|}
\hline \multirow{3}{*}{ Zompanhias } & \multirow{3}{*}{ Período } & \multicolumn{8}{|c|}{ Dividendos eiou JSCP Pagos Informados pelas Cias (em R \$ mil) } & \multicolumn{4}{|c|}{ Total Distribuído (em R \$ mil) } \\
\hline & & \multicolumn{4}{|c|}{ Ord. } & \multicolumn{4}{|c|}{ Pref. A } & \multirow{2}{*}{ Dividendos } & \multirow{2}{*}{ JSCP } & \multirow{2}{*}{$\begin{array}{c}\text { JSCP } \\
\text { Líquido IR }\end{array}$} & \multirow{2}{*}{ Total } \\
\hline & & Div. plaç. & Div. Total & JSCP p/aç. & JSCP Total & Div. plaç. & Div. Total & JSCP p/aç. & JSCP Total & & & & \\
\hline \multirow{3}{*}{ CIA A } & 2003 & 0,0000000 & - & 0,0000000 & - & 0,0000000 & - & 0,0000000 & - & - & - & - & - \\
\hline & 2002 & 0,0000000 & - & 0,0000000 & - & 0,0000000 & - & 0,0000000 & - & - & - & - & - \\
\hline & 2001 & 0,0000000 & - & 0,0018546 & 9.257 & 0,0000000 & - & 0,0020400 & 20.010 & - & 29.267 & 24.877 & 24.877 \\
\hline \multirow{3}{*}{ CIA B } & 2003 & 0,0000000 & - & 0,1415132 & 12.397 & 0,0000000 & - & 0,1556645 & 2.603 & - & 15.000 & 12.750 & 12.750 \\
\hline & 2002 & 0,0000000 & - & 0,1415132 & 12.397 & 0,0000000 & - & 0,1556645 & 2.603 & - & 15.000 & 12.750 & 12.750 \\
\hline & 2001 & 0,0418533 & 3.666 & 0,1173670 & 10.281 & 0,0460386 & 770 & 0,1291040 & 2.159 & 4.436 & 12.441 & 10.574 & 15.011 \\
\hline \multirow{3}{*}{ CIA C } & 2003 & 1,0000000 & 634.168 & 4,1500000 & 2.631 .799 & 1,0000000 & 462.370 & 4,1500000 & 1.918 .833 & 1.096 .538 & 4.550 .632 & 3.868 .038 & 4.964 .575 \\
\hline & 2002 & 0,5286500 & 335.253 & 2,0000000 & 1.268 .337 & 0,5286500 & 244.132 & 2,0000000 & 913.738 & 579.385 & 2.182 .075 & 1.854 .764 & 2.434 .149 \\
\hline & 2001 & 1,3300000 & 843.444 & 1,9700000 & 1.249 .312 & 1,3300000 & 601.074 & 1,9700000 & 890.313 & 1.444 .518 & 2.139 .625 & 1.818 .681 & 3.263 .200 \\
\hline
\end{tabular}

Fonte: os autores

Tabela 6: Cálculo da Remuneração dos Acionistas de A cordo com os Estatutos Sociais das Companhias

\begin{tabular}{|c|c|c|c|c|c|c|c|c|c|c|c|c|c|c|c|c|c|c|}
\hline \multirow{3}{*}{ Companhias } & \multirow{3}{*}{ Período } & \multicolumn{14}{|c|}{ Distribuição dos Resultados - Premissas da Pesquisa (em R\$ mil) } & \multicolumn{3}{|c|}{ Total Distribuído (em R\$ mil) } \\
\hline & & \multicolumn{7}{|c|}{ Ord. } & \multicolumn{7}{|c|}{ Pref. } & \multirow[b]{2}{*}{ JSCP } & \multirow[b]{2}{*}{ Dividendos } & \multirow[b]{2}{*}{ Total } \\
\hline & & \begin{tabular}{|c|} 
JSCP imput. \\
Dive Ohri. \\
\end{tabular} & $\begin{array}{c}\text { Compl. } \\
\text { ISCP }\end{array}$ & Total JSCP & $\begin{array}{c}\text { Compl. } \\
\text { Dis, Ohrie. }\end{array}$ & $\begin{array}{c}\text { Divid. } \\
\text { Derlaradno }\end{array}$ & \begin{tabular}{c|} 
Total \\
Dividensins
\end{tabular} & \begin{tabular}{|c} 
Total \\
Distrihuidn
\end{tabular} & \begin{tabular}{|c|} 
JSCP imput. \\
Dive Ohri.
\end{tabular} & \begin{tabular}{|c|}
$\begin{array}{c}\text { Compl. } \\
\text { ISCP }\end{array}$ \\
\end{tabular} & Total JSCP & \begin{tabular}{|c|} 
Compl. \\
Dis, Ohrima
\end{tabular} & $\begin{array}{c}\text { Divid. } \\
\text { Declaradin }\end{array}$ & $\begin{array}{c}\text { Total } \\
\text { Dividendos }\end{array}$ & \begin{tabular}{|c|} 
Total \\
Distrihuidno \\
\end{tabular} & & & \\
\hline \multirow{3}{*}{ CIA A } & 2003 & - & - & - & - & - & - & $\cdot$ & $\cdot$ & $\cdot$ & - & - & $\cdot$ & $\cdot$ & $\cdot$ & - & $\cdot$ & - \\
\hline & 2002 & - & $\cdot$ & - & $\cdot$ & $\cdot$ & - & - & $\cdot$ & $\cdot$ & $\cdot$ & $\cdot$ & $\cdot$ & $\cdot$ & $\cdot$ & - & - & - \\
\hline & 2001 & 1.589 & 6.279 & 7.868 & - & - & - & 7.868 & 3.435 & 13.574 & 17.009 & - & - & - & 17.009 & 24.877 & - & 24.877 \\
\hline \multirow{3}{*}{ CIA B } & 2003 & 3.257 & 7.280 & 10.537 & - & - & - & 10.537 & 684 & 1.529 & 2.213 & - & - & - & 2.213 & 12.750 & - & 12.750 \\
\hline & 2002 & 4.183 & 6.355 & 10.537 & - & . & - & 10.537 & 878 & 1.334 & 2.213 & - & - & - & 2.213 & 12.750 & - & 12.750 \\
\hline & 2001 & 8.739 & - & 8.739 & 2.323 & 1.343 & 3.666 & 12.406 & 1.835 & - & 1.835 & 488 & 282 & 770 & 2.605 & 10.574 & 4.436 & 15.011 \\
\hline \multirow{3}{*}{ CIA C } & 2003 & 2.237 .029 & - & 2.237 .029 & 121.671 & 512.497 & 634.168 & 2.871 .198 & 1.631 .008 & $\cdot$ & 1.631 .008 & 376.535 & 85.834 & 462.370 & 2.093.378 & 3.868 .038 & 1.096 .538 & 4.964 .575 \\
\hline & 2002 & 1.078 .086 & - & 1.078 .086 & 80.530 & 254.723 & 335.253 & 1.413 .339 & 776.677 & - & 776.677 & 197.183 & 46.949 & 244.132 & 1.020 .809 & 1.854 .764 & 579.385 & 2.434 .149 \\
\hline & 2001 & 1.061 .915 & - & 1.061 .915 & 599.162 & 244.282 & 843.444 & 1.905 .359 & 756.766 & - & 756.766 & 560.536 & 40.539 & 601.074 & 1.357 .841 & 1.818 .681 & 1.444 .518 & 3.263 .200 \\
\hline
\end{tabular}

\section{Fonte: osautores}


Outro dado relevante, equenos permite inferir o porquê da divulgação dos JSCP pelos valores brutos, residena informação de que, no exerć́cio de 2001, a companhiacomplementou em R $\$ 0,2$ bilhão os dividendos recebidos como JSCP, pelos acionistas imunes e isentos de tributação, referentes aos exercícios de 1998, 1999 e 2000, que receberam os JSCP, à época, líquidos de IR. A partir de 2001, passou a divulgar apenas os JSCP brutos, alertando para a retenção de IRRF de 15\%.

\section{CONSIDERAÇÕ ES FINAIS}

As empresas dispõem de um mecanismo que lhes permite pagar menos imposto, quando da distribuição de seu lucro. Tal vantagem ocorre, na medida em que podem usufruiro benefício fiscal decorrentedautilização dosJuros sobre o Capital Próprio, para remunerar o acionista, e, ainda, o benefício societário de compensá-lo com os dividendos obrigatórios.

No decorrer deste trabalho, foram abordadas as formas de remuneração dos acionistas (dividendos e Juros so bre o Capital Próprio), retratados os aspectos financeiro, fiscal e contábil dosJSCP, assim como foi analisada a política de remuneração das companhias abertas do setor de petróleo nacional, nos anos de 2001 a 2003.

O resultado da análise das companhias selecionadas permite inferir que a questão da imputação dosJSCP aos dividendos ainda gera confusão e dúvidas, quanto ao tratamento adequado a ser utilizado pelas companhias. Todas as companhias pesquisadas apresentaram algum problema, quanto à imputação dos dividendos; seja um erro de imputação propriamente dito, seja apenas quanto àqualidade dainformação.

D entre as companhias analisadas, duas parecem não ter observado o estipulado em seus estatutos, quanto à imputação dos JSCP tão somente aos dividendos obrigatórios.

Em pesquisa recente(CostaJr., Martins, Sousa Filho e Cardoso, 2004), divulgada durante a finalização deste trabalho, e que tem como objetivo responder a questões semelhantes as aqui desenvolvidas, das 29 companhias estudadas, apenas 8 não apresentaram erro quanto a imputação dosJSCP ao dividendo obrigatório. Assim sendo, pode-se concluir, com base nos resultados apresentados, que tal problemática deve estar presente em grande número de companhias.

Quanto à evidenciação das informações, todas as companhias analisadas apresentaram problemas na divulgação, seja por omissão, seja por informações conflitantes entre os diversos instrumentos de divulgação, dentre outros, prejudicando a adequada compreensão porparte do usuário dainformação.

Espera-se que este trabalho tenha contribuído para o entendimento do tratamento correto a ser dispensado, quanto à questão da imputação dosJSCP aos dividendos, em especial no setorpetrolífero nacional. Mediante o cenário que encontrado, espera-se chamar a atenção para anecessidade dos órgãos reguladores fiscalizarem as companhias que não observam 0 próprio estatuto social, além do arcabouço legal vigente.
Além disso, deve-se procurar aprimorar a legislação, a fim de favorecer a comparabilidade entre as demonstrações financeiras das empresas e de eliminar, ou pelo menos minimizar, as distorções que ocorrem atualmente.

Como sugestão para novas pesquisas pode-se indicar estudos de natureza qualitativa, de forma mais abrangente, envolvendo uma amostra significativa de empresas, com vistas a investigar a qualidade das informações prestadas, quanto ao uso dos JSCP pelas empresas, visando identificar possíveis causas e/ ou conseqüências do erro de imputação.

\section{REFERÊNCIAS BIBLIOGRÁFICAS}

BRASIL. Lei $n$ ํㅜ 10.303, de 31 de novembro de 2001. . Lei $\mathrm{n}^{0}$ 9.430, de 30 de dezembro de 1996. . Lei $\mathrm{n}$-9.249, de 26 de dezembro de 1995. Lei $n^{0}$ 6.404, de 15 de dezembro de 1976. . D ecreto no 3.000 (RIR/ 99), de 26 de março de 1999. D ecreto no 332, de 04 de novembro de 1991.

BEUREN, Ilse Maria et al. Como elaborar trabalhos monográficos em contabilidade: teoria e prática. BEUREN, Ilse Maria (Org.). São Paulo: Atlas, 2003.

BREALEY, Richard A.; MYERS, Stewart C. Principles of Corporate Finance. Sixth Edition. United States of America: The McGraw Hill Companies, Inc. 2000.

COSTA JR..., Jorge Vieira da. Dividendos e JSCP: como imputalos corretamente? In: Boletim IOB - Temática Contábil e Balanços. São Paulo, n. 6 e n. 7, 2004.

_ MARTINS, Eliseu; SOUSA FILHO, Rodolfo de Castro; CARD O SO , Ricardo Lopes. JSCP e dividendos: as companhias "vacas leiteiras" estão utilizando a sistemática de imputação nos termos da lei?. Anais do 4ํㅡㄹ Congresso USP de Contabilidade e Controladoria. São Paulo, FEA/ USP, 2004.

COMISSÃO DE VALORES MOBILIÁRIOS. D eliberação nํㅜ 207, de 13 de dezembro de 1996.

DAMODARAN, Aswath. Corporate Finanœ: theory and practice. United States: John Wiley \& Sons Inc. 1997.

GIL. Antonio Carlos. Como elaborar projetos de pesquisa. 3. ed. São Paulo: Atlas, 1996.

IUD ÍCIBUS, Sérgio de; MARTINS, Eliseu; GELBCKE, Ernesto Rubens. Manual de contabilidade das sociedades por ações: aplicável às demais sociedades. 5. ed. rev. e atual. São Paulo: Atlas, 2000.

NEVES, Silvério das; VICECO NTI, Paulo Eduardo V. Contabilidade avançada eanálise das demonstrações financeiras. 10 ed. ampl., rev. e atual. São Paulo: Frase, 2001.

SECRETARIA DA RECEITA FED ERAL. Instrução Normativa no 12, de 10 de fevereiro de 1999.

. Instrução Normativa no 41, de 22 de abril de 1998. 
. Instrução Normativa no 93, de 24 de dezembro de 1997. . Instrução Normativa n 11, de 21 de fevereiro de 1996. . Parecer Normativo no 20, de 31 de março de 1987.

SILVA, Carlos Eduardo Vieira da; MARQUES, José Augusto Veiga da Costa. O il \& gás accounting: 0 estudo de caso de uma empresa de petróleo. In: Anaisdo 280 Encontro da ANPAD - EnANPAD (CD ROM). Curitiba, 25 a 29 de set. de 2004.

SOARES JR. Leonildo. Modelo para avaliação do impacto dos juros sobre o capital próprio na estrutura de capital e no fluxo de caixa das empresas. Florianópolis, 2001. D issertação (Mestrado em Engenharia de Produção) Universidade Federal de Santa Catarina.

THOMAS, José Eduardo. et al. Fundamentos de engenharia de petróleo. THO MAS, José Eduardo (O rg). Rio de Janeiro: Interciência/ Petrobras, 2001.

YIN, Robert K. Estudo de caso: planejamento e métodos. 2 ed. Porto Alegre: Bookman, 2001. 